\title{
EVALUATE OF THE PREVALENCE AND SEVERITY OF SYMPTOMS OF TEMPOROMANDIBULAR JOINT DYSFUNCTION (TMJD).
}

\footnotetext{
1. BDS, FCPS

Associate Professor

Sindh Institute of Oral Health

Sciences,

JSM University, Karachi.

2. BDS

Dental Surgeon

LUMHS, Jamshoro.

3. BDS, FCPS

Associate Professor

Dr. Ishrat-UI-Ebad Khan Institute of Oral Health Sciences,

Dow University, Karachi.

4. BDS

Dental Surgeon

Bibi Aseefa Dental College, Larkana.

5. BDS, FCPS

Assistant Professor

Shahida Islam Medical and Dental College Lodhran

6. BDS, FCPS

Assistant Professor Prosthodontics Bibi Aseefa Dental College, Larkana.

Correspondence Address:

Dr. Safia Khatoon

Sindh Institute of Oral Health

Sciences,

JSM University, Karachi.

drsafia_omfs@yahoo.com

Article received on:

18/06/2019

Accepted for publication:

$17 / 02 / 2020$
}

\section{INTRODUCTION}

The temporomandibular joint is the articulation between the lower and upper jaws. The teeth form the contacts between the lower and upper jaws while muscles move the mandible. ${ }^{1}$

Temporo-Mandibular Joint Disorders cause pain in the jaws and / or surrounding muscles, leading to significant pain, distress and functional disturbance / limitations. ${ }^{2,3}$ TMJD is the most prevailing musculoskeletal condition after chronic low back pain.

For clinical and research settings, current diagnostic criteria for Temporomandibular Disorders (DC/TMD) ${ }^{4}$ defines 12 common TMD including but not limited to Arthralgia, Myalgia,
Local Myalgia, Myofascial pain, Myofascial pain with referral, four-disc displacement disorders, Degenerative joint disease, Subluxation and Headache attributed to TMD. ${ }^{5,6}$

Common symptoms present in patients of TMD are toothache, facial pain, TMJ joint sounds, earache and limited jaw movements. Often these patients present in dental clinics with complain of toothache because they naturally assume that tooth is causing the problem. Consequently, it is imperative for the dentist to recognize these patients, diagnose the actual cause of the symptoms, ascertain their needs and select appropriate treatment / intervention options. ${ }^{7}$

The etiology of TMJD is fairly complex and 
multifactorial, including structural abnormalities of TMJ, stress induced muscle hyperactivity and overuse of joint. ${ }^{8}$ In 1973, a research study proposed four (4) foremost theories underlying the etiology of temporomandibular disorders (TMDs), whereby two of these were psychological and psycho-physiologic. ${ }^{9}$

Diagnosis of TMJD is carried out by evaluating patients' history with subsequent physical examination. $^{10}$ Additionally, diagnostic TMJ imaging methods provide an assessment of TMJ components' integrity and their functional association which confirm the extent and/ or progression of existing disease. ${ }^{11}$ These disorders are most common among the 20-45 years age group with an increasing tendency in female gender. Following are the symptoms of temporomandibular joint syndrome. ${ }^{12}$

- Chronic pain described as dull ache, routinely unilateral in the muscles of mastication.

- Pain is worsened when chewing and may radiate to the jaw and ear.

- Locking of jaws when he/she attempts to open the mouth.

- Ear (preauricular) clicking or popping, typically when displacement of the articular disk is present.

- Headache and/ or neck ache. In some cases, patient complains headache without localized pain in the temporomandibular joint.

- An uncomfortable or different from typical bite. ${ }^{13}$

- Neck pain with shoulder involvement with accompanying back pain.

- Bruxism i.e. involuntarily or unconsciously clenching or grinding the teeth, typically during sleep

- Pain intensifies over the course of the day.

- History of trauma to the jaw (upper / lower).

TMJDs have the potential to cause severe mental and physical handicaps in patients. Early diagnosis of TMJDs is vital in limiting longterm harm and disability in patients. Its etiology includes several contributing factors which can be eliminated or largely reduced by instituting various preventive measures. ${ }^{14}$ Therefore, along with early diagnosis, patients must be educated about preventive measures to decrease the burden of this disease among the local population. ${ }^{15}$

The objective of this study is to evaluate the prevalence and severity of TMJD and distribution of associated symptoms with respect to age and gender among the patients visiting Dental Clinic of a Rural Health Centre (RHC). This study is first of its kind, conducted in rural areas of Sindh. It provides data on the prevalence and severity of temporomandibular joint disorders in the subject population.

\section{MATERIAL \& METHODS}

This is a descriptive cross-sectional study carried out at Dental Clinic of Rural Health Centre (RHC) Nasirabad, District Kambar Shadadkot (Sindh, Pakistan) from December 2018 to May 2019. The study sample comprises of total 132 patients meeting the inclusion and exclusion criteria. Along with patient history, a thorough clinical examination is carried out to establish the prevalence and severity of temporomandibular joint disorders using Fonseca's Questionnaire and Fonseca's Anamnestic Index (IAF). Patients are categorized on basis of presenting symptoms and frequencies for various categorical variables like gender, age group etc are calculated.

\section{Inclusion Criteria}

- Patients of both genders with age ranging from 15 to 70 years.

- All patients diagnosed with TMD having symptoms of pain, clicking and limited mouth opening.

- Patients who have previously received treatment for TMDs.

\section{Exclusion Criteria}

- Patients with organic dental disease and other disorders which may mimic TMJD pain.

- Patients with bone diseases like Osteoporosis, osteopetrosis or osteomalacia.

- Patients with debilitating diseases including rheumatoid arthritis, poliomyelitis or chronic obstructive pulmonary disease.

- Patients with neurological disease including Dyskinesia (Abnormality in performing voluntary muscle movements). 
- Female patients with pregnancy.

- Patients with any previous history of Orthodontic treatment, Cleft surgery or Orthognathic surgery.

\section{Data Collection Procedure}

A detailed history is obtained from each patient based on Fonseca's Questionnaire (Table-I). Follow-on oral examination is carried out to evaluate and rule out any other organic or dental condition which may mimic symptoms of TMD.

Patients are assessed on basis of symptoms such as facial pain, TMJ tenderness, locking / stiffness or tenderness of jaw muscles, joint sounds, limitations in mandibular movement and difficulty in chewing. Patients presenting with one or more of these symptoms are included in the study. The severity is assessed and diagnosis of type of TMD is carried out using Fonseca's Anamnestic Index (IAF) (Table-II). Data collected from patients is entered in SPSS ${ }^{\circledR}$ version 16.0 for statistical analysis.

\section{RESULTS}

Out of total 132 patients, $88(67 \%)$ are females while remaining 44 (33\%) patients are male (Figure-1). The age of patients is categorized into 3 Groups as shown in Table-III with $50 \%$ patients belonging to Age Group 1, 27.3\% in Group 2 and $22.7 \%$ in Group 3 with mean age of $\sim 38$ years. Gender Distribution with respect to Age group is shown in Table-IV. The distribution of patients based on their response to Fonseca's Questionnaire is presented in Table-V. $43 \%$ answers are positive for subjective symptoms based on "Yes" and "Sometimes" Due to normative population, the prevalence of "No" answer is high. The frequency of positive responses to Fonseca's Questionnaire (Table-VI) reveals that majority of patients reports positive for neck pain or stiff neck (15\%) and muscular fatigue while chewing (15\%). $14 \%$ of patients complains of frequent headaches while $12 \%$ reports clicking or popping during opening of mouth. Other $12 \%$ considers themselves tense or nervous. $10 \%$ of patients complains of earache or pain at TMJ area together with 9\% giving positive history of clenching or grinding of their teeth. $5 \%$ are positive for discomfort while chewing their food with side to side movement of their jaws, while only $4 \%$ patient's think that their teeth do not articulate well and $4 \%$ finds it difficult to open their mouth.

Figure-2 shows the distribution of patients with respect to TMJD severity according to Fonseca's Anamnestic Index. Data shows 65.9 \% patients have Mild TMJD, $18.9 \%$ patients have Moderate TMJD, while only $1.5 \%$ patients present with Severe TMJD.

Table-VII shows the distribution of patients' response to Fonseca's Questionnaire according to Gender. From the answers to the Fonseca's Questions, the severity of TMJD symptoms with respect to gender and age group is evaluated and is presented in Table-VIII and Table-IX respectively. A total of $94.3 \%$.females suffer with some degree of TMD An analysis of cross tabulation between Fonseca Anamnestic index with respect to gender shows that there is no case of Severe TMJD in males whereas 02 females present with symptoms of Severe TMJD 19.3 $\%$ females shows Moderate TMJD symptoms while $18 \%$ males have Moderate TMJD $72.7 \%$ females showed symptoms of Mild TMJD while $52.7 \%$ males have Mild TMJD. Results showed that overall prevalence of Mild TMJD symptoms is common in Age Group 1 (15 - 35 years).

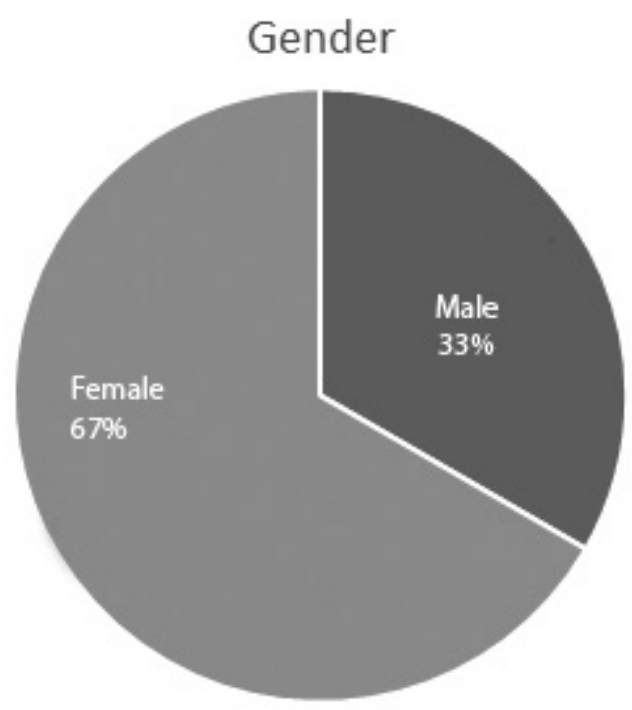

Figure-1. Gender distribution of patients 


\begin{tabular}{|l|l|l|l|}
\hline \multicolumn{1}{|c|}{ Question } & Yes & No & \\
\hline Is it difficult for you to open your mouth? & & \\
\hline Is it difficult for you to move mandible from side to side? & & \\
\hline Do you get tired or have pain during chewing food? & & \\
\hline Do you have recurrent headaches? & & \\
\hline DO you have any pain on the nape or stiff neck? & & \\
\hline Do you have recurrent earaches or pain in craniomandibular joints? & & \\
\hline $\begin{array}{l}\text { Have you noticed any TMJ clicking when you open your mouth or } \\
\text { during chewing? }\end{array}$ & & \\
\hline Do you clench or grind your teeth? & & \\
\hline Do you feel your teeth do not articulate well? & \\
\hline Do you consider yourself an anxious / nervous / tense patient? & & \\
\hline
\end{tabular}

Table-I. Fonseca's questionnaire

\begin{tabular}{|c|l|}
\hline Points & No TMJD \\
\hline $0-15$ & Mild TMJD \\
\hline $20-40$ & Moderate TMJD \\
\hline $45-65$ & Severe TMJD \\
\hline
\end{tabular}

Table-II. Fonseca's anamnestic index (IAF)

\begin{tabular}{|c|c|c|c|}
\hline Age Group & Age (Years) & Frequency of Patients & Mean Age \\
\hline 1 & $15-35$ & $66(50.0 \%)$ \\
\hline 2 & $36-50$ & $36(27.3 \%)$ & \multirow{3}{*}{37.98} \\
\hline 3 & $51-70$ & $30(22.7 \%)$ & \\
\hline & Table-III. Age distribution of patients \\
\hline
\end{tabular}

\begin{tabular}{|l|c|c|c|c|}
\hline \multirow{2}{*}{ Gender } & \multicolumn{3}{|c|}{ Age Group } & Total \\
\hline Male & $\mathbf{1}$ & $\mathbf{2}$ & $\mathbf{3}$ & 44 \\
\hline Female & 29 & 6 & 9 & 88 \\
\hline
\end{tabular}

Table-IV. Gender distribution with respect to age group

\begin{tabular}{|l|c|c|c|}
\hline \multicolumn{1}{|c|}{ Question } & Yes & No & Sometimes \\
\hline Is it difficult for you to open your mouth? & $9(6.8 \%)$ & $111(84.1 \%)$ & $12(9.1 \%)$ \\
\hline Is it difficult for you to move mandible from side to side? & $11(8.3 \%)$ & $104(78.8 \%)$ & $17(12.9 \%)$ \\
\hline Do you get tired or have pain during chewing food? & $55(41.7 \%)$ & $48(36.4 \%)$ & $29(22.0 \%)$ \\
\hline Do you have recurrent headaches? & $43(32.6 \%)$ & $53(40.2 \%)$ & $36(27.3 \%)$ \\
\hline Do you have any pain on the nape or stiff neck? & $57(43.2 \%)$ & $45(34.1 \%)$ & $30(22.7 \%)$ \\
\hline Do you have recurrent earaches or pain in craniomandibular joints? & $21(15.9 \%)$ & $74(56.1 \%)$ & $37(28.0 \%)$ \\
\hline $\begin{array}{l}\text { Have you noticed any TMJ clicking when you open your mouth or } \\
\text { during chewing? }\end{array}$ & $29(22.0 \%)$ & $65(49.3 \%)$ & $38.8 \%)$ \\
\hline Do you clench or grind your teeth? & $24(10.6 \%)$ & $83(62.9 \%)$ & $25(18.9 \%)$ \\
\hline Do you feel your teeth do not articulate well? & $16(12.1 \%)$ & $108(81.8 \%)$ & $8(6.1 \%)$ \\
\hline Do you consider yourself an anxious / nervous / tense patient? & $31(23.5 \%)$ & $64(48.5 \%)$ & $37(28.0 \%)$ \\
\hline
\end{tabular}

Table-V. Patients' response to fonseca's questionnaire 


\section{Question}

Is it difficult for you to open your mouth?

Is it difficult for you to move mandible from side to side?

Do you get tired or have pain during chewing food?

Do you have recurrent headaches?

Do you have any pain on the nape or stiff neck?

Do you have recurrent earaches or pain in craniomandibular joints?

Have you noticed any TMJ clicking when you open your mouth or during chewing?

Do you clench or grind your teeth?

Do you feel your teeth do not articulate well?

Do you consider yourself an anxious / nervous / tense patient?

\begin{tabular}{|l|l|}
\hline $\begin{array}{c}\text { Frequency of Positive Answers } \\
\text { (Yes and Sometimes) }\end{array}$ & Frequency (\%) \\
\hline 21 & $4 \%$ \\
\hline 28 & $5 \%$ \\
\hline 84 & $15 \%$ \\
\hline 79 & $14 \%$ \\
\hline 87 & $15 \%$ \\
\hline 58 & $10 \%$ \\
\hline 67 & $12 \%$ \\
\hline 49 & $9 \%$ \\
\hline 24 & $4 \%$ \\
\hline 68 & $12 \%$ \\
\hline
\end{tabular}

Table-VI. Frequency of Positive Responses to Fonseca's Questionnaire

\begin{tabular}{|c|c|c|c|c|}
\hline \multirow{2}{*}{ Question } & \multirow{2}{*}{ Response } & \multicolumn{2}{|c|}{ Gender } & \multirow{2}{*}{ P-Value } \\
\hline & & Male & Female & \\
\hline \multirow{3}{*}{ Is it difficult for you to open your mouth? } & Yes & 4 & 5 & \multirow{3}{*}{0.360} \\
\hline & No & 38 & 73 & \\
\hline & Sometime & 2 & 10 & \\
\hline \multirow{3}{*}{$\begin{array}{l}\text { Is it difficult for you to move mandible from side to } \\
\text { side? }\end{array}$} & Yes & 3 & 8 & \multirow{3}{*}{0.280} \\
\hline & No & 38 & 66 & \\
\hline & Sometime & 3 & 14 & \\
\hline \multirow{3}{*}{ Do you get tired or have pain during chewing food? } & Yes & 13 & 42 & \multirow{3}{*}{0.002} \\
\hline & No & 25 & 23 & \\
\hline & Sometime & 6 & 23 & \\
\hline \multirow{3}{*}{ Do you have recurrent headaches? } & Yes & 11 & 32 & \multirow{3}{*}{0.404} \\
\hline & No & 19 & 34 & \\
\hline & Sometime & 14 & 22 & \\
\hline \multirow{3}{*}{ Do you have recurrent headaches? } & Yes & 13 & 44 & \multirow{3}{*}{0.64} \\
\hline & No & 20 & 25 & \\
\hline & Sometime & 11 & 19 & \\
\hline \multirow{3}{*}{$\begin{array}{l}\text { Do you have recurrent earaches or pain in } \\
\text { craniomandibular Joints? }\end{array}$} & Yes & 5 & 21 & \multirow{3}{*}{0.91} \\
\hline & No & 31 & 43 & \\
\hline & Sometime & 8 & 29 & \\
\hline \multirow{3}{*}{$\begin{array}{l}\text { Have you noticed any TMJ clicking when you open } \\
\text { your mouth or during chewing? }\end{array}$} & Yes & 8 & 21 & \multirow{3}{*}{0.451} \\
\hline & No & 26 & 39 & \\
\hline & Sometime & 10 & 28 & \\
\hline \multirow{3}{*}{ Do you clench or grind your teeth? } & Yes & 10 & 14 & \multirow{3}{*}{0.545} \\
\hline & No & 25 & 58 & \\
\hline & Sometime & 9 & 16 & \\
\hline \multirow{3}{*}{ Do you feel your teeth do not articulate well? } & Yes & 7 & 9 & \multirow{3}{*}{0.385} \\
\hline & No & 35 & 73 & \\
\hline & Sometime & 2 & 6 & \\
\hline \multirow{3}{*}{$\begin{array}{l}\text { Do you consider yourself an anxious / nervous / } \\
\text { tense patient? }\end{array}$} & Yes & 8 & 23 & \multirow{3}{*}{0.111} \\
\hline & No & 27 & 37 & \\
\hline & Sometime & 9 & 28 & \\
\hline
\end{tabular}




\begin{tabular}{|l|c|c|c|c|c|}
\hline \multicolumn{1}{|c|}{ Gender } & \multicolumn{3}{|c|}{ Fonseca's Anamnestic Index } & Pearson Chi Square & P-Value \\
\hline & No TMJD & Mild TMJD & $\begin{array}{c}\text { Moderate } \\
\text { TMJD }\end{array}$ & $\begin{array}{c}\text { Severe } \\
\text { TMJD }\end{array}$ & \multirow{2}{*}{15.132} \\
\hline Male & 13 & 23 & 8 & 0 & 2 \\
\hline Female & 5 & 64 & 17 & 2.002 \\
\hline Total Patients & $18(13.6 \%)$ & $87(65.9 \%)$ & $25(18.9 \%)$ & $2(1.5 \%)$ & \\
\hline
\end{tabular}

Table-VIII. TMJD severity classification with respect to gender

\begin{tabular}{|c|c|c|c|c|c|c|}
\hline \multirow{2}{*}{$\begin{array}{c}\text { Age } \\
\text { Group }\end{array}$} & No TMJD & Mild TMJD & $\begin{array}{c}\text { Moderate } \\
\text { TMJD }\end{array}$ & $\begin{array}{c}\text { Severe } \\
\text { TMJD }\end{array}$ & Total & Pearson Chi Square \\
\hline 1 & 6 & 47 & 11 & 2 & 66 & \multirow{2}{*}{ P-Value } \\
\hline 2 & 4 & 23 & 9 & 0 & 36 & 0.556 \\
\hline 3 & 8 & 17 & 5 & 0 & 30 \\
\hline Total & 18 & 87 & 25 & 2 & 132 & \\
\hline & & Table-IX. TMJD Severity Classification with Respect to Age & \\
\hline
\end{tabular}

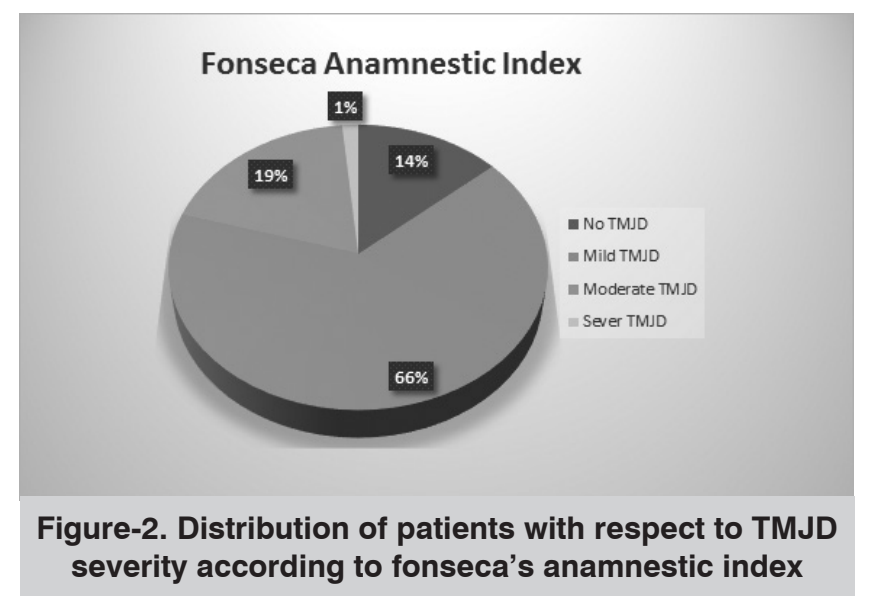

\section{DISCUSSION}

This cross-sectional descriptive study carried out amongst the patients visiting Dental Clinic of RHC Nasirabad, provides an outline of prevalence of TMD's symptoms in Nasirabad. This study is first among rural areas of Sindh to evaluate the presence of TMDs symptoms which are often misdiagnosed by inexperienced dental clinicians. In this study, $43 \%$ answers are positive for subjective symptoms based on "Yes" and "Sometimes", while Agerberg and Carlsson $^{16}$ and Szentpetery et al $^{17}$ found that $57 \%$ and $20.6 \%$ patients have reported subjective symptoms respectively. The results of this study suggest overwhelming female predilection which corroborate the previous finding of Pedroni et $\mathrm{al}^{18}$, Garcia et $\mathrm{al}^{19}$, and Otuyemi et al. ${ }^{20}$ Nevertheless, it is recommended that a detailed clinical examination and mental health assessment of female patients in these settings be carried out to elicit reasons of high prevalence in female gender.

Nomura et $\mathrm{al}^{21}$ had found that $35.78 \%$ of patients have mild TMJD, $11.93 \%$ of patients had moderate TMJD and $5.5 \%$ of patients had severe TMJD. Wänman and Agerberg ${ }^{22}$ had determined that $13 \%$ and $7 \%$ patients had moderate and severe TMJD respectively. Yet another study conducted by Rieder et $\mathrm{al}^{23}$ had determined that $10.3 \%$ individuals suffered from advanced and severe TMJD. Although the results of this study corroborate with previous findings, it further establishes that mild TMJD is $65.9 \%$, moderate TMJD is $18.9 \%$ and severe TMJD is only $1.5 \%$ in rural population of Sindh. This can be explained by the fact that people in rural areas are inherently having little rest due extensive manual work in agricultural fields. Other reason could be inability of clinicians to diagnose initial concealed symptoms which can be prevented from further aggressiveness.

With respect to gender, the results of this study, $94.3 \%$, corroborate the findings of Garcia et al. ${ }^{24}$, Solberg et al. ${ }^{25}$ Shiau and Chang. ${ }^{26}$ Higher prevalence of signs associated with mandibular disorder have been reported in female gender in these studies. The higher prevalence of women diagnosed with some degree of TMD may be related to physiologic differences in female 
gender e.g. regular variations in hormone levels, muscular structure and characteristics of the conjunctive tissue etc. Further investigations are recommended to elicit the limitations of this study such as smaller sample size and inability to evaluate the cause of TMDs.

Some investigators ${ }^{27}$ suggested that TMJDs were most prevalent after 30 years of age. Our sample showed $15-35$ years of age is more affected with Mild TMJD symptoms. ${ }^{28}$ This could be from the fact that these ages face many social pressures or other socioeconomics issues which result in development of anxiety or stress leading to TMJD symptoms.

\section{CONCLUSION}

This study concludes that TMJD are more common in females with age group of 15 - 35 years of age. The most prevalent symptom is muscular pain / tiredness of jaws during chewing and stiffness of neck. In this study sample, majority of patients suffer from Mild TMJD symptoms.

This study is only fraction of epidemiological investigation required to provide basis for understanding these disorders. Further studies using similar methods need to be evaluated in other selected populations.

Copyright@ 17 Feb, 2020.

\section{REFERENCES}

1. Jacobs T, Sawaengkit P. National Institute of Dental and Craniofacial Research efficacy trials of bionator Class II treatment: a review. The Angle orthodontist. 2002 Dec;72(6):571-5.

2. Auvenshine RC. Temporomandibular disorders: associated features. Dental Clinics. 2007 Jan 1;51(1):105-27.

3. Fillingim RB, Ohrbach R, Greenspan JD, Knott C, Dubner R, Bair E, Baraian C, Slade GD, Maixner W. Potential psychosocial risk factors for chronic TMD: descriptive data and empirically identified domains from the OPPERA case-control study. The Journal of Pain. 2011 Nov 1;12(11):T46-60.
4. Schiffman E, Ohrbach R, Truelove E, Look J, Anderson G, Goulet JP, List T, Svensson P. Diagnostic criteria for temporomandibular disorders (DC/TMD) for clinical and research applications: recommendations of the International RDC/TMD Consortium Network and Orofacial Pain Special Interest Group. Journal of oral \& facial pain and headache. 2014;28(1):6.

5. Auvenshine RC. Temporomandibular disorders: associated features. Dental Clinics. 2007 Jan 1;51(1):105-27.

6. Fillingim RB, Ohrbach R, Greenspan JD, Knott C, Dubner R, Bair E, Baraian C, Slade GD, Maixner W. Potential psychosocial risk factors for chronic TMD: descriptive data and empirically identified domains from the OPPERA case-control study. The Journal of Pain. 2011 Nov 1;12(11):T46-60.

7. Cunha S.C., Nogueira R.V.B., Duarte A.P., Vasconcelos B.C.E., Almeida R.A.C., Análise Dos Índices De Helkimo E Craniomandibu-Lar Para Diagnóstico De Desordens Temporomandibulares Empacientes Com Artrite Reumatoide. Braz J Otorhinolaryngol. 2007; 73:19---26

8. Liu F., Steinkeler A., Epidemiology, diagnosis, and treatment of temporomandibular disorders. Dental Clinics of North America. 2013 31; 57(3):465-79.

9. Boever JD. Functional disturbances of the temporomandibular joints. Oral sciences reviews. 1973;2:100.

10. Silveira AM, Feltrin PP, Zanetti RV, Mautoni MC. Prevalência deportadores de DTM em pacientes avaliados no setor de otorri-nolaringologia. Braz J Otorhinolaryngol. 2007; 73:528---32

11. Ferreira LA, Grossman E, Januzzi E, Queirozde Paula MV, Carvalho ACP, Diagnosis of temporomandibular joint disorders: indication of imaging exams. MayJune 2016, Volume 82, Issue 3, Pages 341-352.

12. Vasconcelos BCE, Silva EDO, Kelner N, Miranda KS, Silva AFC. Meios de diagnóstico das desordens temporomandibulares. RevCir Traumat Buco-MaxiloFacial. 2002; 1:49---57

13. Leresche L. Epidemiology of temporomandibular disorders: Implications for the investigation of etiologic factors. Crit Rev Oral Biol Med. 1997; 8: 291305.

14. Lewis EL, Dolwick MF, Abramowicz S, Reeder SL. Contemporary imaging of the temporomandibular joint. Dent Clin North Am. 2008; 52:875---90

15. Roda R, Bagán J, Fernández J, Bazán S, Soriano Y. 
Review of temporomandibular joint pathology. Part I: Classification, epidemiology and risk factors. Med Oral Patol Oral Cir Bucal. 2007; 12(4): 292-98.

16. Agerberg G, Carlsson G. Functional disorders of the masticatory system. I. Distribution of symptoms as judged by questionnaire. Acta Odontol Scand 1972; 30: 597-613.

17. Szentpetery A, Hlun E, Fazekas A, Prevalence of mandibular function $m$ an urban population in Hungary. Community Dent Oral Epidemiol 1986; 14: 177-80.

18. Pedroni CR, De Oliveira AS, Guaratini MI. Prevalence study of signs and symptoms of temporomandibular disorders in university students. J Oral Rehabil. 2003; 30(3): 283-89

19. Garcia AR, Lacerda Jr N, Pereira SLS. Grau de disfunção da ATM e dos movimentos mandibulares em adultos jovens. Rev Assoc Paul Cir Dent 1997; 51(1): 46-51.

20. Otuyemi OD, Owotade FJ, Ugboko VI, Ndukwe KC, Olusile OA. Prevalence of signs and symptoms of temporomandibular disorders in young Nigerian adults. J Orthod. 2000; 27(1): 61-65

21. Nomura K, Vitti M, Oliveira AS, Chaves TC, Semprini M, Siessere S, et al. Use of the Fonseca's questionnaire to assess the prevalence and severity of temporomandibular disorders in Brazilian dental undergraduates. Braz Dent J. 2007; 18(2): 163-67.

22. Carvalho GF, Chaves TC, Florencio LL, Dach F, Bigal ME, Bevilaqua-Grossi D. Reduced thermal threshold in patients with temporomandibular disorders. J Oral Rehabil. 20161 ; 43(6):401- 08.
23. Manfredini D, Poggio CE. Prosthodontic planning in patients with temporomandibular disorders and/or bruxism: A systematic review. J Prost Dent. 2017 1; 117(5):606-13.

24. Garcia AR, Lacerda Junior N, Pereira SL. Grau de disfunçäo da ATM e dos Movimentos Mandibulares em adultos jovens. Rev. Assoc. Paul. Cir. Dent. 1997;51(1):46-51.

25. Solberg WK, Woo MW, Houston JB. Prevalence of mandibular dysfunction in young adults. The Journal of the American Dental Association. 1979 Jan $1 ; 98(1): 25-34$

26. Shiau YY, Chang C. An epidemiological study of temporomandibular disorders in university students of Taiwan. Community dentistry and oral epidemiology. 1992 Feb;20(1):43-7.

27. Conti PC, FerreiraPM, PegoraroLF, ContiJV, Salvador MC. A cross-sectional study of prevalence and etiology of signs and symptoms of temporomandibular disorders in high school and university students. J Orofacial Pain. 1996 1; 10(3).

28. De Godoi Goncalves DA, Dal Fabbro AL, Campos JA, Bigal ME, Speciali JG. Symptoms of temporomandibular disorders in the population: An epidemiological study. Journal of orofacial pain. 2010 $1 ; 24(3)$.

\begin{tabular}{|c|c|c|c|}
\hline \multicolumn{4}{|c|}{ AUTHORSHIP AND CONTRIBUTION DECLARATION } \\
\hline Sr. \# & Author(s) Full Name & Contribution to the paper & Author(s) Signature \\
\hline 1 & Safia Khatoon & Idea, Data collection. & \\
\hline 2 & Sarang Suresh & $\begin{array}{l}\text { Introduction, Methodology, } \\
\text { Abstract writing. }\end{array}$ & \\
\hline 3 & Muhammad llyas & $\begin{array}{l}\text { Conclusion and Discussion } \\
\text { writing. }\end{array}$ & \\
\hline 4 & Priya Rani & $\begin{array}{l}\text { Critically reviewed the } \\
\text { manuscript. }\end{array}$ & \\
\hline 5 & Maimuna Khokhar & $\begin{array}{l}\text { Referencing and literature } \\
\text { review. }\end{array}$ & \\
\hline 6 & & $\begin{array}{l}\text { Proof reading and literature } \\
\text { review. }\end{array}$ & \\
\hline
\end{tabular}

